\title{
Investigation Effects of Different Wind Turbine Designs on Air Flow and Generated Power
}

\author{
Hazim Moria $^{1 *}$, Abdalfadel Younis ${ }^{2}$, Monaem Elmnifi $^{3}$ and Mohammad Rasidi Rasani ${ }^{4}$ \\ ${ }^{1}$ Department of Mechanical Engineering Technology, Yanbu Industrial College, Yanbu Al-Sinaiyah City 41912, \\ Kingdom of Saudi Arabia \\ ${ }^{2}$ Second Department of Mechanical Engineering, University of Omar Al-Mukhtar, Libya \\ ${ }^{3}$ Department of Mechanical Engineering, Bright Star University, Libya \\ ${ }^{4}$ Department of Mechanical and Manufacturing Engineering, Faculty of Engineering and Built Environment, \\ Universiti Kebangsaan Malaysia, Bangi, 43600 Selangor, Malaysia \\ *Corresponding author's email: Moriah [AT] rcyci.edu.sa
}

\begin{abstract}
This paper describes a study of different designs for the wind turbine. The basic wind turbine configuration with a second smaller rotor mounted in the front of the main rotor to extract as much force as possible from the flow. The wind turbine used in all the simulations was an upwind turbine with a $3 \mathrm{MW}$ horizontal axis. The behaviors of pressures, velocities, and power generated were simulated and discussed. Three different configurations have been designed and simulated in SolidWorks at four different wind velocities ranging from 10 to 40 mph with an increment of $10 \mathrm{mph}$. The results revealed that the power generated by the rotor of the dual turbine to the rotor of the conventional turbine, the power created by the conventional turbine's rotor is higher even though the size is the same. Furthermore, adding a diffuser equipped with a plat-type circular frame achieved the best performance. Finally, some numbers and figures are highlighted, and a conclusion is stated to summarize the results.
\end{abstract}

Keywords- Wind Turbine; Dual Wind Turbine; Air Flow; Power; Shroud.

\section{INTRODUCTION}

The wind is a result of unequal heating to Earth by the solar radiation emitted by the sun. Due to this heating, the temperature of air varies from region to another, causing the phenomenon of convection, which creates a pressure gradient that forces air to start moving horizontally in forms of streams [1,2]. This movement generates kinetic energy that we feel in the wind. For a long time, wind energy has been used in different ways. Some studies refer to the first usage of wind energy to the period between 500-900 A.D when it used to be utilized to run windmills, which were used to grind wheat and other grains. [3-5]. As the world population is growing, the demand for energy is also increasing. On the other hand, for more than a century, the energy industry has expanded and improved. The renewable energy sector is one of those that has been increasing and proliferating.

Renewable energies such as wind have been studied and developed, so the increasing demand of power is met. Wind energy has genuinely come of age during the past three decades. Especially during the last ten years, the usage of wind power has increased for generating electrical power by using new technologies, different designs, and configurations of wind turbines [6-10]. The wind turbine converts the wind kinetic energy into mechanical power, which generates electrical power by running a generator. The fundamental role of the wind turbine exerts the forces on airfoils of the rotor blades. The rotor is transferring the rotational motion to a connected shaft and a generator that rotates, changing the mechanical power to electrical power [11]. The wind turbines' designs vary from each other to fulfill the best performance and increase the efficiency of the turbines themselves. Over the last 25 years, designers have focused their efforts on designing and manufacturing larger and taller turbines to reach upper layers where air moves with higher speed. Hence, getting more airflow with higher speed according to wind profile power law. These days, most of the wind turbines are used to generate electricity are horizontal axis (HAWTs). All HAWTs have standard components such as a tower, rotor with blades, and generator [12]. The essential components among all these components are the blades that play a significant role in converting the force exerted by the flow of air to rotational motion. In this paper, several designs of wind turbines were studied and investigated to determine the best design in terms of increasing airflow towards the blades and the produced power. 


\section{DESIGNS AND SIMULATION}

Nowadays, there are different designs of airfoils used by many companies to gain energy from winds. In this paper, Younis and Jenkins developed all designs of wind turbines used for simulations over the period 2015 to 2017 [2,3,10]. The samples of a wind turbine were created in SolidWorks, and Vestas V90-3MW wind turbine closely followed in the present study. Tables 1 and 2 summarizes the primary dimensions of the nacelle, rotor, tower, and hub of the wind turbine.

Table 1: Dimensions of nacelle and Rotor

\begin{tabular}{cccc}
\hline \multicolumn{1}{c}{ Nacelle } & \multicolumn{2}{c}{ Rotor } \\
\hline Height $(\mathrm{m})$ & 4 & Diameter $(\mathrm{m})$ & 90.17 \\
Length $(\mathrm{m})$ & 9.65 & Swept Area $\left(\mathrm{m}^{2}\right)$ & 5109.6 \\
Width $(\mathrm{m})$ & 8.85 & Blade Length $(\mathrm{m})$ & 34.63 \\
\hline
\end{tabular}

Table 2: Dimensions of tower and hub

\begin{tabular}{ccll}
\hline Hub & \multicolumn{3}{c}{ Tower } \\
\hline Maximum Diameter (m) & 3.6 & & \\
Maximum Width (m) & 4.2 & Height (m) & 105 \\
Length (m) & 4.4 & & \\
\hline
\end{tabular}

The design of wind turbines used in this study is similar for all the specific wind turbine model used for all three simulations. All the wind turbine used in the simulations was a $3 \mathrm{MW}$ horizontal axis upwind turbine [13]. All the designs have the same components, but different from each other with additional components, such as adding a small rotor or a diffuser equipped with a ring. The essential components of a wind turbine are the blades that change the kinetic energy of wind to kinetic energy, rotational motion. The working principle of all the airfoils types is the same. The wind stream flows over the airfoil can be divided into two categories, the air upper and the air lower the particles of air start traveling with higher speed than those at the lower surface, causing a difference of pressure on both sides, according to Bernoulli's theorem. The pressure of the fluid decreases at points where the speed of the fluid increases. The pressure at the airfoil lower surface is higher than the pressure on the upper surface at airspeeds variation for both sides. The two different pressures formed on both sides of the blade resulted from a lift force which acts on the lower side, pushing the blades and making them turn.

This work aims to study other designs besides the basic model. Intending to improve the performance of the conventional wind turbine, Younis and Jenkins have designed a wind turbine that is shrouded by varying types of shrouds that equipped with rings to increase the speed and quantity of flowing air towards the blades [2,3,10]. The basic model with a second smaller rotor fitted in the front of the original rotor to extract as much force as possible from the flow. The behaviors of pressures, velocities, and power produced were discussed and simulated using SolidWorks with several designs. Different speeds of air varied from 10 to $40 \mathrm{mph}$ with an increment of $10 \mathrm{mph}$.

\subsection{Subheadings}

There are multiple types of simulations used in SolidWorks. One of these simulations is a flow simulation used to animate all types of fluids' flow that could be applicable for fluid mechanics. When setting a flow simulation in SolidWorks, it needs to be chosen whether the simulation is internal or external. For the conventional wind turbine, an external flow simulation was set since there are no cavities or interior spaces. During the simulation of the primary wind turbine, the airspeeds were applied towards the rotor's blades. Then, both pressures and velocities trajectories were formed in forms of colored lines over the blades, as shown in Figure 1. The trajectories translated into a number, and the values of pressure and velocities on the front and back sides of the blades were measured.

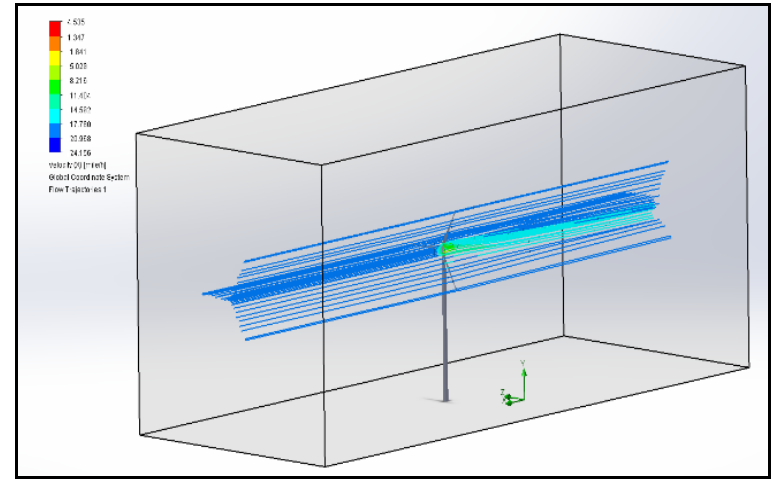

a 


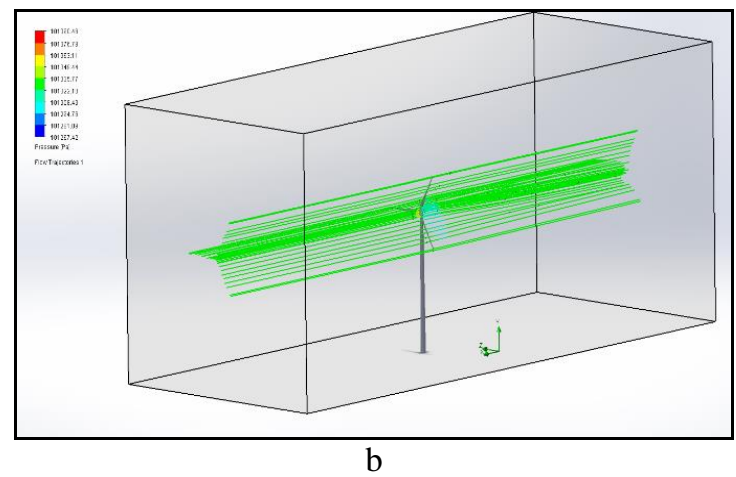

Figure 1: (a) Streamline of flow colored according to velocity; (b) pressure

\subsection{Dual Wind Turbine Design and Simulation}

Intending to create a dual wind turbine, Younis et al. have added a smaller rotor integrated on the same hub of the bigger rotor [10]. The dual wind turbine has the same dimensions as the conventional wind turbine. However, the dual wind turbine is featured with a smaller rotor that is $80 \%$ smaller than the original rotor, as shown in Table 3.

Table 3: Dimensions of front and rare rotors

\begin{tabular}{ccc}
\hline Dimensions & Rear rotor & Front rotor \\
\hline Rotor diameter $(\mathrm{m})$ & 90.17 & 72.14 \\
Swept area $\left(\mathrm{m}^{2}\right)$ & 6387 & 5109.6 \\
Blade length $(\mathrm{m})$ & 43.28 & 34.63 \\
\hline
\end{tabular}

Younis et al. have designed one more rotor, which is $60 \%$ lower than the original rotor, with varying the distance between the two rotors beginning from $1.5 \mathrm{~m}$ up to $4 \mathrm{~m}$ [10]. In this study, the design animated the dual wind turbine by adding only an $80 \%$ smaller rotor set $3 \mathrm{~m}$ away from the original rotor. An external stimulation was used in the conventional design, also used for the dual wind turbine. The trajectories of the flows translated the velocities and pressures into numbers. Figure 2 demonstrated the velocity and flow streamline with different gradient colors.

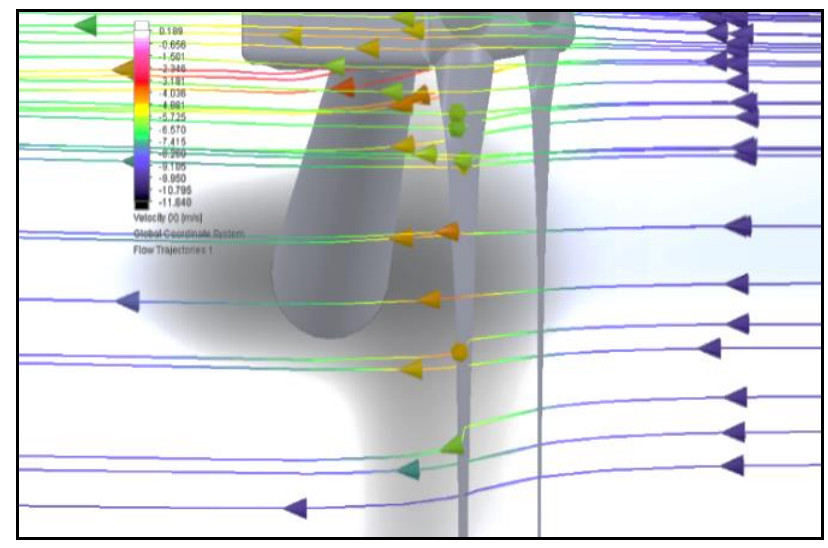

Figure 2: Velocity \& flow streamline

\section{SHROUDED WIND TURBINE}

Shrouded wind turbines first appeared in the 20th century when Dew Oliver produced the first wind wheel with a diffuser surrounding the blades [8]. The shrouded design was modern verses of ones. However, shrouded wind turbines flanged diffuser wind turbines that have been developed by Ohya et al. are equipped with amended diffusers and brims [15]. Adding these components enhances the performance of shrouded wind turbines and produces more power units allowing a reduction in sizes and costs. The hidden turbine can influence on the diffuser and brim working principle. If the airflow is applied towards an extended diffuser, the flow accelerates at the diffuser inlet. Additionally, inserting a plat-type circular frame or flange called brim, which allocated at the end of the diffuser, vortices are created behind it. The vortices will create a low-pressure area behind the diffuser producing a pressure gradient on both sides of the shroud, bringing more flow into the shroud as shown in Figure 3. In other words, the presence of both diffusers and brims resulted in an increase in mass flows drawn into the diffuser. Therefore, at the shroud inlet, the velocity of the winds gets higher, causing the turbine blades to spin at a higher speed, resulting in more generated turbine power [9-10]. 


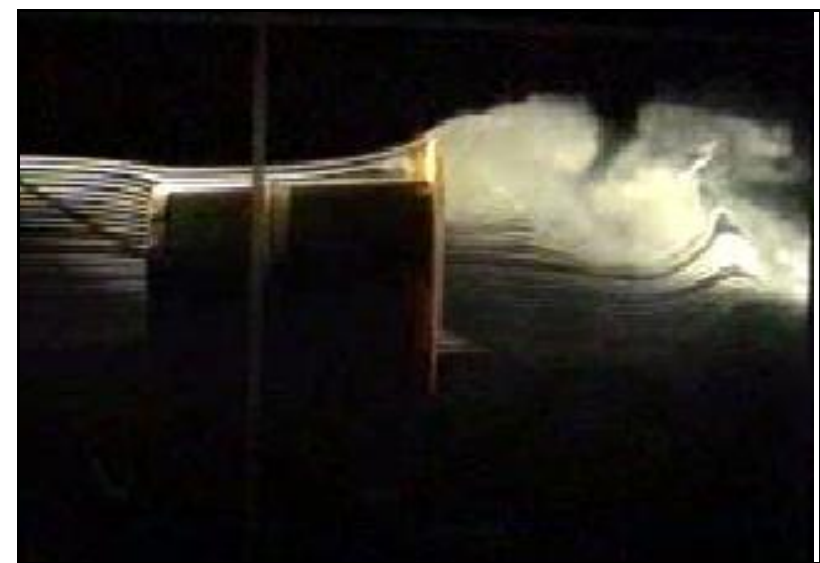

Figure 3: Flow simulation of flow within diffusers [9]

\subsection{Shrouded Turbine Design}

The shrouded wind turbine has the same dimension of the particular design in terms of the basic parts. The only additional component is the shroud. In this part, the dimensions of the shroud are demonstrated. Yonis and Jenkins have developed multiple types of shrouds that are designed originally by Ohya et al. According to the idea of the working principle of diffusers and brims, the more extended diffuser and larger brim mean getting more flow with high speed at the entrance of the shroud. However, as highlighted previously by Younis and Jenkins, a longer diffuser design with a huge brim affected the structure of a turbine gravely by increasing weights and stresses on them. Figure 4 illustrated the dimensions of the shrouded wind turbine were defined based on the rotor diameter (Dr):

$$
\begin{aligned}
& L t=0.371 D \\
& L=L t / 2 \\
& h=0.5 D \\
& D=[D r+(0.02 D r)] \\
& S=(D-D r) / 2
\end{aligned}
$$

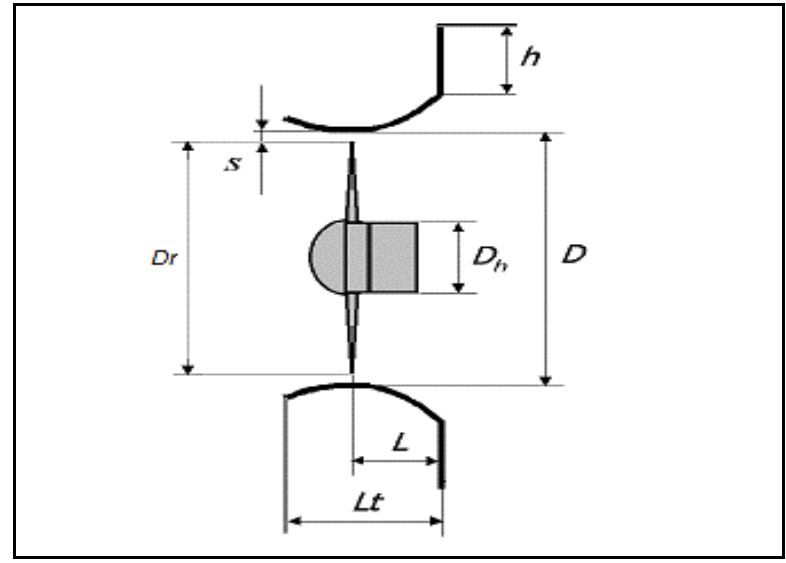

Figure 4: Dimensions of the shrouded wind turbine

\subsection{Shrouded Wind Turbine Simulation}

Since the shroud has cavities in the internal spaces, the internal flow simulation was used, which achieved by switching from the external flow simulation to the internal one. A virtual wind tunnel is required to run an internal simulation on SolidWorks with cavities and interior spaces. Any parameters did not rule the sizes and dimensions of the used tunnel. However, the internal diameter of the tunnel must be larger than the height of the turbine. Also, the length of the tunnel should be long enough to allow winds to have enough space to flow toward the blades of the turbine. Figure 5 displayed the front-side section of the tunnel integrated with the turbine. 


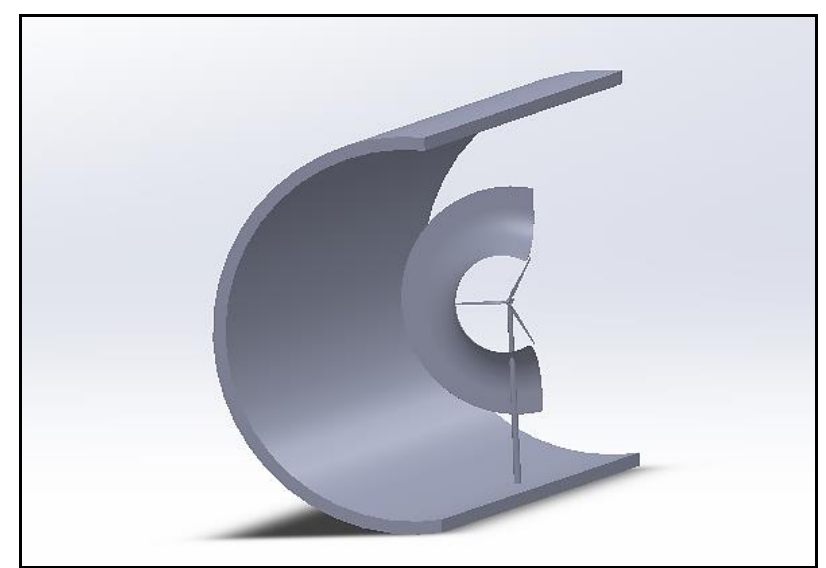

Figure 5: Front-side section of a shrouded turbine on SolidWorks

The flow turbine of both pressure and velocity was drawn. The pressure and velocity were generated so that both shifts interpreted in numerical value forms. The flow trajectories indicated that vortices exist behind the shrouded due to the nature of both diffuser and brim. The vortices created a low-pressure area and allowing for an increase in airflow within the diffuser. Figure 6 shows the forming of vortexes behind shroud's brim. Also, Figure 7 (a, b) illustrates the gradients of velocity and pressure emphasized.

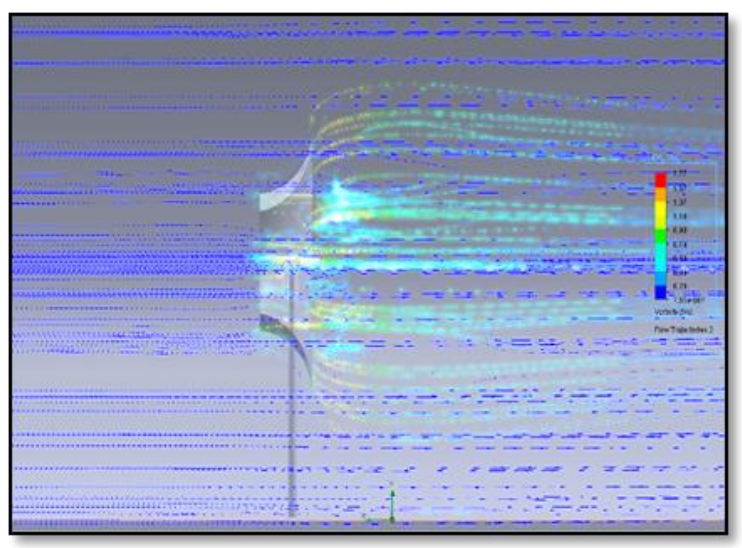

Figure 6: Forming of vortexes behind shroud's brim

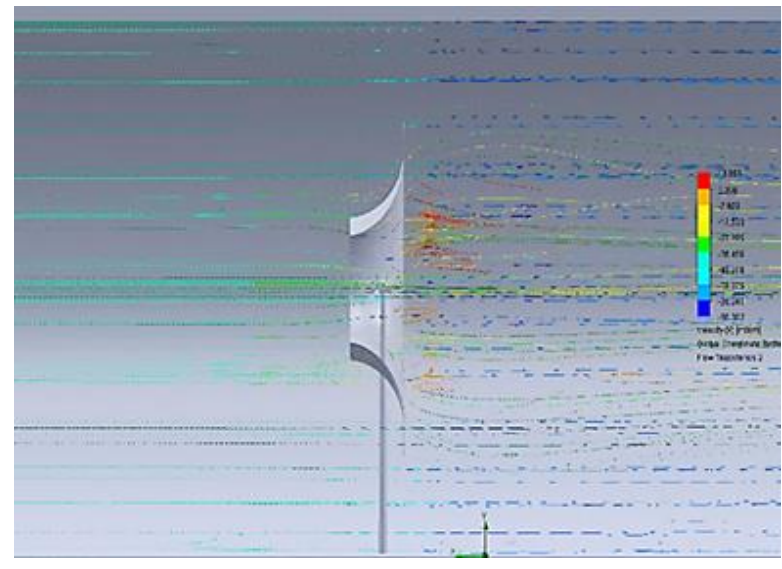

a

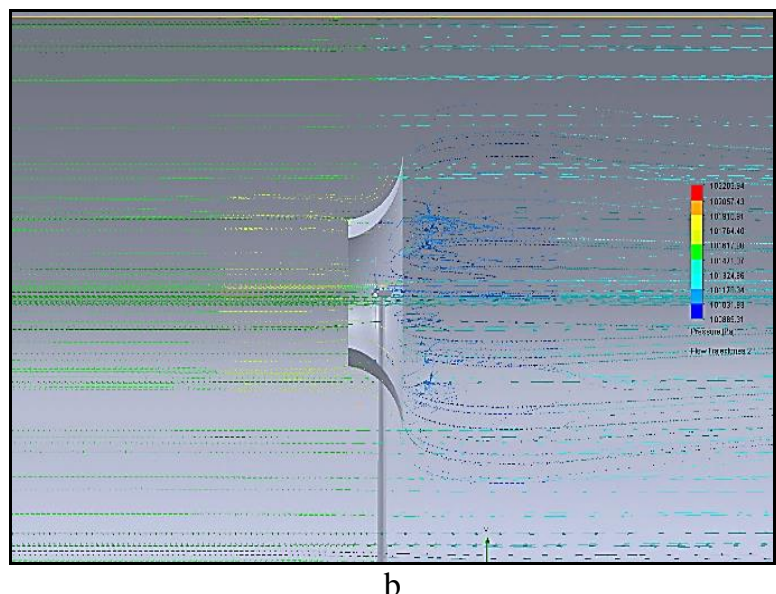

b

Figure 7: (a) flow streamlined colored according to velocity; (b) pressure

\section{EES PROGRAMMING}

The software Engineering Equations Solver (EES) was used to estimate the power generated from the standard, dual, and shrouded turbines at various velocities. The performance of a wind turbine can be estimated using various methods, including Weibull or Rayleigh analysis [1]. The Rayleigh distribution used in this research to estimate the efficiency and power generated by the wind turbines. 


\subsection{Governing Equations}

The efficiency $(\eta)$ was determined from equation 6, according to the distribution of Rayleigh. The annual delivered energy, as stated in equation 7, can be estimated from the number of hours per year. The turbine capacity factor (CF) calculated from Equation 8. While the rated power (Pr) estimated from the power curve as presented in Figure 8. The real wind energy was determined from the measured average power multiplied by the number of hours per year, as indicated in equation 9.

$$
\begin{aligned}
& \eta=\frac{E_{\text {annual }}}{E_{\text {wind }}} \\
& E_{\text {annual }}=8760 \times \operatorname{Pr} \times C F \\
& C F=0.087 \times\left(15-\frac{P r}{D r^{2}}\right) \\
& E_{\text {wind }}=8760 \times P r
\end{aligned}
$$

The average power in equation 9 can be estimated as a function of the rotor's swept area air density and cubic of the measured wind velocity, which can be seen in equation 10 .

$$
\operatorname{Pr}=\frac{6}{\pi} \times \frac{1}{2} \times \rho_{\text {air }} \times A_{\text {rotor }} \times V r^{3}
$$

Another parameter used to determine wind turbine efficiency is the actual power generated, which is the net power produced at the generator output. As stated in equation 1, the average actual power generated is equal to the output multiplied by the wind energy. The power of wind can be obtained by using equation 12 .

$$
\begin{aligned}
& \bar{P}_{\text {act }}=\eta \times \bar{P}_{\text {wind }} \\
& \bar{P}_{\text {wind }}=\frac{6}{\pi} \times \frac{1}{2} \times \rho_{\text {air }} \times A_{\text {rotor }} \times \bar{v}^{3}
\end{aligned}
$$

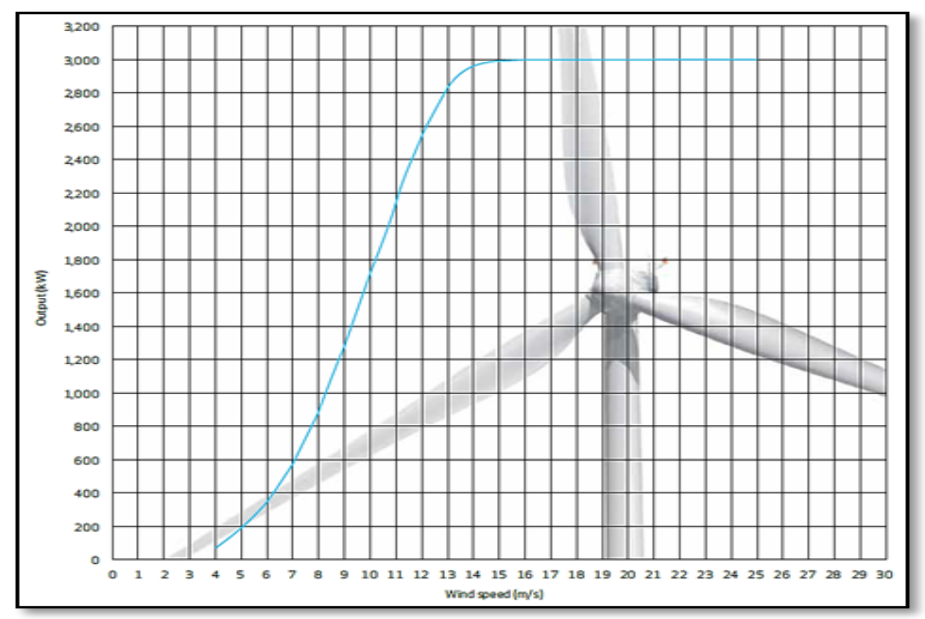

Figure 8: Power curve of V90-3.0 MW wind turbine [11]

Since the conventional, dual, and shrouded wind turbines using the same model equations (6-12) can be applied in all the designs. Nevertheless, the only variable that differs from each other was the frontal airspeed of wind at the original rotors' blades surfaces, which is the main parameter that affected the power obtained from the wind. The numerical values of the frontal wind speeds for all configurations at every single applied speed, are clarified in Tables 4, 5, and 6.

Table 4: Applied wind velocity on a conventional wind turbine and corresponding blades' surface front velocity

\begin{tabular}{cc}
\hline Applied wind velocity (mph) & Front velocity (m/s) \\
\hline 10 & 3.91 \\
20 & 9.12 \\
30 & 11.59 \\
40 & 15.71 \\
\hline
\end{tabular}

Table 5: Applied wind velocity on a shrouded wind turbine and corresponding blades' surface front velocity

\begin{tabular}{cc}
\hline Applied wind velocity $(\mathbf{m p h})$ & Front velocity $(\mathbf{m} / \mathbf{s})$ \\
\hline 10 & 12.28 \\
20 & 24.69 \\
30 & 38.12 \\
40 & 51.03 \\
\hline
\end{tabular}


Table 6: Applied wind velocity on a dual wind turbine and corresponding blades' surface front velocity

\begin{tabular}{ccc}
\hline $\begin{array}{c}\text { Applied wind velocity } \\
(\mathbf{m p h})\end{array}$ & $\begin{array}{c}\text { Front velocity at smaller rotor } \\
(\mathbf{m} / \mathbf{s})\end{array}$ & $\begin{array}{c}\text { Front velocity at bigger rotor } \\
(\mathbf{m} / \mathbf{s})\end{array}$ \\
\hline 10 & 3.92 & 2.47 \\
20 & 9.12 & 4.79 \\
30 & 11.59 & 7.98 \\
40 & 15.71 & 11.92 \\
\hline
\end{tabular}

\section{RESULTS AND DISCUSSION}

The result of the simulation of both SolidWorks and EES was plotted to show the variance between them. The critical parameters were considered the front pressure and velocity and the power generated.

\subsection{Front Pressure}

Front pressure was measured pressure during the simulation over the front surface of the original rotor of all types. Along with Figure 9, in the case of the conventional wind turbine, the introduction of more velocity blocks the flow to the blades due to the reduction of flow layers close to the blade surface, which increases the flow pressure. However, for the dual wind turbine and because of the flowing over the smaller impeller, vortices form behind the small rotor, generating a low-pressure region precisely in front of the blades of the bigger rotor, which reduced the pressure slightly. The shroud and brim, front pressure declined when stepping up the speed of winds. For example, the result of the front pressure is $101177.21 \mathrm{~Pa}$ at ten $\mathrm{mph}$ wind velocity, while the front pressure $100855.23 \mathrm{~Pa}$ at 40 mph wind velocity. The front pressure gradient is $91091 \mathrm{~Pa}$, which is vast compared to the gradient resulting from the addition of a smaller rotor as for the dual turbine. The result highlights the diffuser impact on the turbine output.

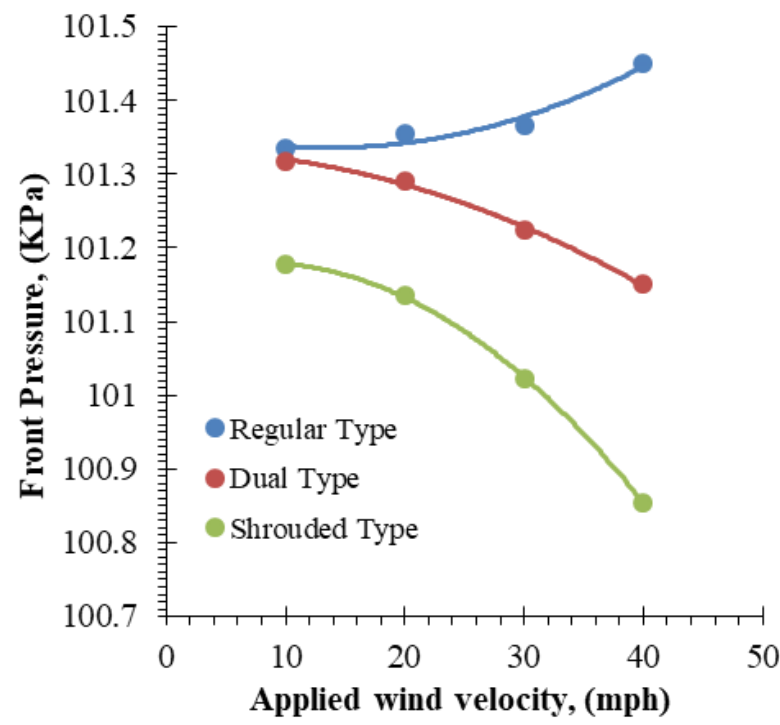

Figure 9: Applied speeds against front pressures

\subsection{Front Speed}

The front side velocity is the stream towards the turbines' original rotor blades surface. Figure 10 shows that the conventional design increase in the front velocity is not as significant due to wind energy loss as part of it blocked by the blades and dispersed away from the blades. For example, at a velocity of $40 \mathrm{mph}$, the resulting in front is $15.71 \mathrm{~m} / \mathrm{s}$, which is lower in comparison to those for the shrouded turbine. The existence of the smaller rotor in the dual wind turbine is a part of the flow that blocked and dispersed away from the blades. The formation of vortices is behind the smaller rotor's blades in the absence of any recoveries of the flow towards the larger rotor speed. The shrouded turbine, the pressure in front of the blades reduced, and the pressure behind them. The reduction of the pressure was due to the velocity recovery induced by the low-pressure area generated by the brim downstream of the shroud. The velocity boosts the flow at the shroud inlet, according to Bernoulli's equation for flowing inside diffusers, resulting in more produced electrical power. 


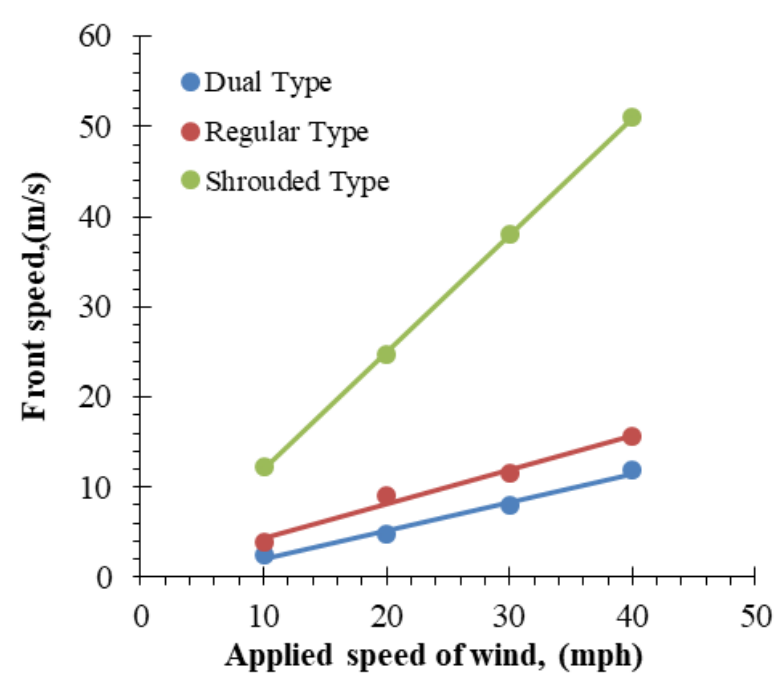

Figure 10: Applied velocities against front velocities

\subsection{Actual Generated Power}

Figure 11 shows the considerable differences in the power generated by particular, dual turbines, and shrouded turbines. The curves present the generated power from all turbines at varying wind velocities. The conventional design of the produced power varied from $50.09 \mathrm{~kW}$ up to $3227 \mathrm{~kW}$. While for the same applied velocity on the dual turbine, the generated rear rotor power is lower than the generated conventional turbine's rotor power. That is because of significant losses in wind energy due to the addition of the small front rotor. The power values produced by the dual turbine and varied from $2.185 \mathrm{~kW}$ up to $244.38 \mathrm{~kW}$. However, the shrouded design generated much power. The power generated by the shrouded design varied from $231.6 \mathrm{~kW}$ up to $6901 \mathrm{~kW}$. The value is much larger in comparison to those for both conventional and dual wind turbines. The boost in the generated power of the shrouded turbine is associated with the low-pressure region behind the brim. Due to the design of the diffuser, the pressure of the entering flow decreases, causing the flow towards the blades, to accelerate yielding increase power generation.

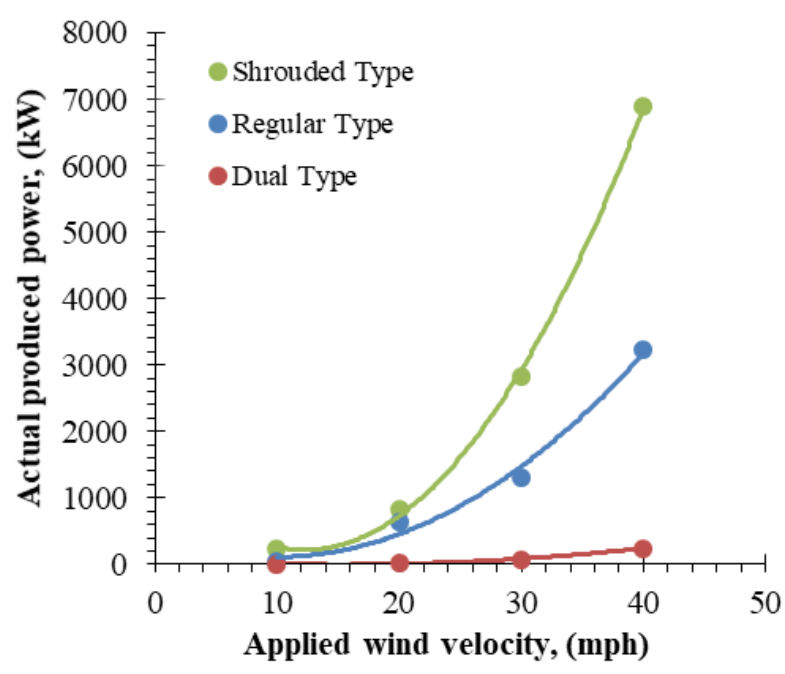

Figure 11: Applied velocities against actual power

\section{CONCLUSION}

In seeking to meet the increasing demand for electricity around the world, and due to the issues associated with conventional energy sources, several renewable energy technics have been developed. One of these technics is wind energy used to generate electricity via wind turbines. Varieties of designs were created and studied by both scientists and engineers. Three configurations were designed by Younis and Jenkins and analyzed in this study. According to the analysis, the increment of the power generated by the conventional turbine, adding a small secondary rotor, increases the total power produced. However, comparing the power generated by the dual turbine's rotor to the conventional turbine's rotor, the power produced by the conventional turbine's rotor is higher even though the size is the same. Because of the 
smaller rotor that blocked the flow toward the rear rotor due to the absence of recovery for the dispersed flow. The best performance could achieve by a wind turbine is when to add a diffuser equipped with a plat-type circular frame (brim). That recovers the pressure and causes a low-pressure region behind the shrouded, which makes the flow of wind to be concentrated towards the turbine's blades an increased speed of flow, which increases the amount of produced power.

\section{REFERENCES}

[1] Duffie, J. A., \& Beckman, W. (2013). Solar engineering of thermal processes. New Jersey: John Wiley \& Sons. Inc;.

[2] Jenkins, P. E., Younis, A., \& Chen, Y. (2017). Design and Analysis of a Dual Rotor Turbine with a Shroud Using Flow Simulations. Journal of Power and Energy Engineering, 5(04), 25.

[3] Jenkins, P. E., \& Younis, A. (2016). Flow Simulation to Determine the Effects of Shrouds on the Performance of Wind Turbines. Journal of Power and Energy Engineering, 4(08), 79.

[4] Ozbay, A., Tian, W., \& Hu, H. (2014). An experimental investigation on the aeromechanics and near wake characteristics of dual-rotor wind turbines (drwts). In 32nd ASME Wind Energy Symposium (p. 1085).

[5] Jenkins, P. E., Younis, A., \& Chen, Y. (2017). Design and Analysis of a Dual Rotor Turbine with a Shroud Using Flow Simulations. Journal of Power and Energy Engineering, 5(04), 25.

[6] Rosenberg, A. J. (2016). A computational analysis of wind turbine and wind farm aerodynamics with a focus on dual rotor wind turbines.

[7] Nugroho, S., Diana, L., Pratilastiarso, J., Giarnayoga, W. A., \& Ariyanti, D. P. (2018, October). Computational Performance and Aerodynamic Analysis of Multisage Wind turbin with Dual Rotor. In 2018 International Conference on Applied Science and Technology (iCAST) (pp. 607-612). IEEE.

[8] Scheuermann, J. P. (2017). Wind flow through shrouded wind turbines. Naval Postgraduate School Monterey United States.

[9] Rosenberg, A., Selvaraj, S., \& Sharma, A. (2014). A novel dual-rotor turbine for increased wind energy capture. In Journal of Physics: Conference Series (Vol. 524, No. 1, p. 012078). IOP Publishing.

[10] Jenkins, P. E., \& Younis, A. (2016). Flow Simulation to Determine the Effects of Shrouds on the Performance of Wind Turbines. Journal of Power and Energy Engineering, 4(08), 79.

[11] Sathyajith, M., \& Philip, G. S. (Eds.). (2011). Advances in wind energy conversion technology. Springer Science \& Business Media.

[12] Toshimitsu, K., Narihara, T., Kikugawa, H., Akiyoshi, A., \& Kawazu, Y. (2017). Experimental study of improved HAWT performance in simulated natural wind by an active controlled multi-fan wind tunnel. Journal of Thermal Science, 26(2), 113-118.

[13] Willey, L. D. (2010). Design and development of megawatt wind turbines (pp. 206-231). Southampton, UK: WIT Press.

[14] Green, C. (2009). Ducted or augmented turbines. Retrieved fromhttp://www.wind-works.org

[15] Ohya, Y., \& Karasudani, T. (2010). A shrouded wind turbine generating high output power with wind-lens technology. Energies, 3(4), 634-649.

[16] Courbois, A., Flamand, O., Toularastel, J. L., Ferrant, P., \& Rousset, J. M. (2011). Applying relevant wind generation techniques to the case of floating wind turbines. In Sixth European and African Conference on Wind Engineering (EACWE), Nantes, France, July (pp. 7-13). 